\title{
Anti-Estrogenic Suppression of the Lordosis Response in Female Rats
}

\section{J. BRADLEY POWERS}

\author{
Neuroscience Laboratory and Department of Psychology, \\ University of Michigan Ann Arbor, Michigan 48104
}

The antiestrogen, $\mathrm{Cl} 628$, was used to suppress the lordosis response induced by sequential injections of estrogen and progesterone in ovariectomized (OVX) female rats. Appropriate doses of CI 628 completely abolished sexual receptivity in females administered estradiol benzoate (EB) in sesame oil. This behavioral effect could be at tenuated by providing increased quantities of $\mathrm{EB}$ or decreased quantities of $\mathrm{Cl}$ 628. Anti-estrogenic effects on lordosis induced by free estradiol in saline (E) were assessed after first establishing behaviorally equivalent doses of EB and E. This was accomplished by determining thresholds for E-induced lordosis. OVX females were approximately seven times less sensitive to E than to EB. CI 628 had no significant effects on E-induced lordosis, in contrast to the complete abolition of lordosis in females treated with behaviorally equivalent EB doses. A possible mechanism to explain this differential responsiveness of EB- and E-treated females is discussed.

\section{INTRODUCTION}

The lordosis response in female rodents can be elicited following estrogen and progesterone stimulation (Lisk, 1973). Considerable progress has been made in characterizing the mechanism of action of these hormones in peripheral tissue (O'Malley and Means, 1974), but how they interact with the central nervous system is less well understood (McEwen, Zigmond, and Gerlach, 1972). Autoradiographic and biochemical studies have demonstrated that certain brain regions posses a high affinity for radioactive estradiol (Pfaff and Keiner, 1973). Although a minimum of coinparable information is available for progesterone, its pattern of uptake in the central nervous system appears different from estradiol (Luttge, Wallis and Hall, 1974; Sar and Stumpf, 1973; Seiki and Hattori, 1973; Wade, Harding, and Feder, 1973; Whalen and Gorzalka, 1974).

The presence of steroid receptors in the brain by itself reveals nothing about their participation in lordosis response mechanisms. However, there can be little doubt that estrogen and progesterone mediate behavioral effects, in part by acting directly on CNS tissue. Brain implants of estrogen or progesterone can influence sexual receptivity in ovariectomized rats, hamsters, 
and guinea pigs (Ciaccio and Lisk, 1973; Morin and Feder, 1974; Powers, 1972), although the areas where each of these hormones may act have not been definitivcly identified (Davidson, 1972; Gorski, 1974; Kow, Malsbury and Pfaff, 1974).

The availability of pharmacologic compounds which antagonize hormone effects in target tissue (Geynet, Millet, Truong, and Baulieu, 1972) offers a different strategy in localizing brain sites responding to gonadal steroids. The use of brain implants of antihormone to investigate neuronanatomical sites of hormonal action may be particularly useful. This is because gonadal steroids most likely affect lordosis by acting on a number of different brain sites, either simultaneously or sequentially. Implantation of antihormone into discrete diencephalic loci at various times would be expected to inhibit the behavioral effect of systemically administered hormone only at those sites which in some way mediate this action of the hormone in the brain.

Because anti-estrogens are more readily available than antiprogestagens, and because steroid uptake in brain is more anatomically localized for estrogen than is the case for progesterone, it would appear more feasible to use anti-estrogens for implant studies.

Prior to any extensive investigation of anti-estrogen applied centrally, it seemed advisable to better understand its behavioral actions when given systemically. Although a number of different anti-estrogenic compounds have been shown to suppress the lordosis response normally observed following appropriate steroid treatment (Komisaruk and Beyer, 1972; McDonald, 1973; Ross, Paup, Brant-Zawadzki, Marshall, and Gorski, 1973; Whalen and Gorzalka, 1973), CI 628 (Callantine, Humphrey, Lee, Windsor, Schottin, and O'Brien, 1966) was chosen for this study because two earlier investigations (Arai and Gorski, 1968; Whalen and Gorzalka, 1973) reported that this drug could unequivocally abolish sexual responding in female rats, and that it was achieving this effect by antagonizing the actions of estrogen but not those of progesterone. In addition, preliminary studies from our own laboratory indicate that CI 628 can exert significant inhibitory effects on lordosis when implanted directly into the hypothalamus.

In the experiments reported below, dose-response functions have been established for the $\mathrm{Cl} 628$ suppression of rat lordosis behavior, and the differential effects of this anti-estrogen on estradiol benzoate vs. free estradiol-induced sexual receptivity have been examined.

\section{GENERAL PROCEDURES}

Sprague-Dawley female rats weighing $250-350 \mathrm{~g}$ were obtained from Spartan Research Animals (Hazlett, Michigan) and caged individually with food and water provided ad lib. An illumination cycle of $14 \mathrm{hr}$ light: $10 \mathrm{hr}$ dark was maintained with the dark period extending from 11A.M. to 9P.M. 
Females were ovariectomized under Equi-Thesin anesthesia, $198 \mathrm{mg} / \mathrm{kg}$ (Jensen-Salsbury, St. Louis, Mo.), at least 2 weeks prior to experimental use.

Sexual receptivity was induced by sequential injections of estrogen and progesterone $(\mathrm{P})$; behavior testing was performed during the dark portion of the illumination cycle 4-6 hr following $P$ treatment. The estrogens used were either estradiol benzoate in sesame oil (EB) or free estradiol in saline (E); both were administered subcutaneously (sc) on a body weight basis such that the volume injected in milliliters equaled 0.5 times weight in kilograms. The time of estrogen injection was designated zero-hr; progesterone $(500 \mu \mathrm{g} /$ animal) was given in $0.10 \mathrm{ml}$ sesame oil sc at $42-\mathrm{hr}$. Various doses of the antiestrogen CI 628 (1-[2-(p-[a-(p-methoxyphenyl)-b-nitrostyryl] phenoxy) ethyl] pyrrolidine, monocitrate) were administered sc in $0.1 \mathrm{ml}$ of $5 \%$ ethanol.

Seven days prior to the beginning of weekly hormone injections and behavior tests, an EB + P "priming sequence" consisting of $40 \mu \mathrm{g} / \mathrm{kg} \mathrm{EB}$, and $500 \mu \mathrm{g} \mathrm{P}$ were injected at zero- and $42-\mathrm{hr}$, respectively. Four to six hours after $P$, females were placed in mating arenas with two to three sexually vigorous males and left for approximately $1 \mathrm{hr}$, but quantitative measures of sexual responsiveness were not obtained. This priming sequence was provided to accustom experimental females to the testing situation and to counteract the attenuated responsiveness to exogenous hormonal stimulation often observed after initial postovariectomy treatments (Beach and Orndoff, 1974).

When receptive behavior was quantified, testing occurred $4-6 \mathrm{hr}$ after $\mathrm{P}$ in semicircular mating arenas $(76 \mathrm{~cm}$ in diameter and $40 \mathrm{~cm}$ in height and width); experimental females were allowed 10 mounts by stud males which had previously been adapted to the arenas for at least $10 \mathrm{~min}$. The quality of lordosis elicited by each of these mounts was rated on a scale from 0-3, representing no lordosis (0) to full rump elevation and maximal dorsiflexion of the vertebral column (3). For each test the mean value of these 10 ratings constituted the receptivity score (RS).

\section{EXPERIMENT I}

In this experiment the sexual receptivity induced by exogenous injections of EB and $P$ was assessed after varying doses of $\mathrm{CI} 628$ had been administered concurrently with the EB. Because preliminary results in this laboratory had indicated that a single injection of anti-estrogen could totally inhibit sexual responsiveness, no attempt was made to vary the number or timing of CI 628 injections.

\section{Methods}

Twelve rats were administered exogenous hormones over 4 successive weeks. During week 1 , all 12 rats were given the $E B+P$ priming sequence. 
The following week, two groups were formed such that within each group the EB dose remained constant over weeks 2-4 (Group A-5 $\mu \mathrm{g} / \mathrm{kg}$; Group B $10 \mu \mathrm{g} / \mathrm{kg}$ ) while the CI 628 dose was varied. These particular estrogen quantities were chosen on the basis of previously established EB thresholds (Powers and Valenstein, 1972). That is, doses were considered optimal which would reliably induce receptive behavior but be low enough to remain sensitive to the anti-estrogenic effects. For both groups, CI 628 was administered at zero-hr (20 min prior to EB injection) in quantities of either 1.0, 0.1, or $0.01 \mathrm{mg} /$ animal. The order in which any particular female received the various anti-estrogen doses over the 3 weeks of testing was varied according to a modified Latin square design, with the restriction that equal numbers of the three doses be used each week for both Groups A and B. The behavioral effects of CI 628 treatment were measured by obtaining weekly receptivity scores for each female following $\mathrm{P}$ injection.

\section{Results}

Sexual receptivity was completely abolished by $1.0 \mathrm{mg}$ CI 628 in five of six females in both the 5 and $10 \mu \mathrm{g} / \mathrm{kg} \mathrm{EB}$ groups (Fig. 1). Decreasing the anti-estrogen dose by a factor of 10 or 100 eliminated its suppressive effects on the lordosis response. Analysis of variance indicated significant antiestrogen dose effects for both EB treatment groups $(p<.0013$ and $<.03$ for 5 and $10 \mu \mathrm{g} / \mathrm{kg} \mathrm{EB}$, respectively, Friedman test).
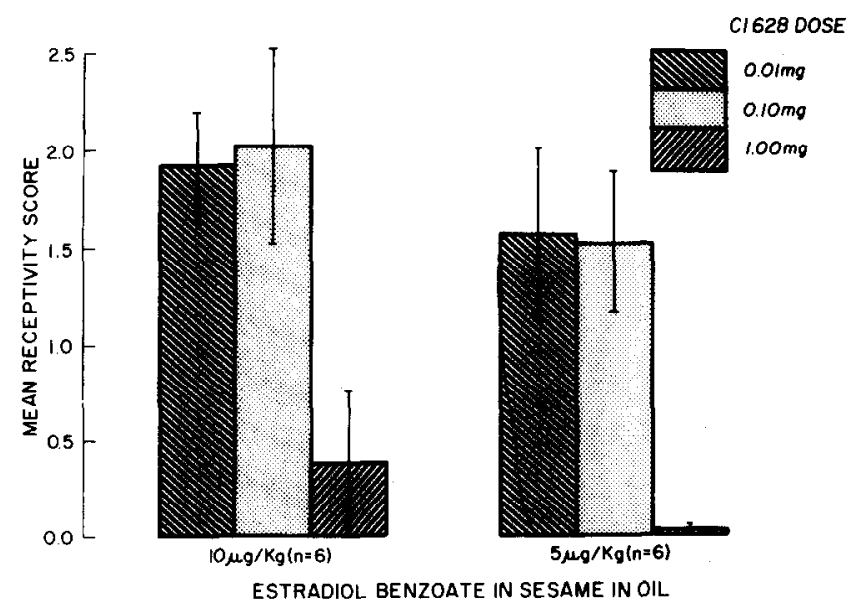

Fig. 1. Receptivity scores (mean \pm SEM) of ovariectomized rats treated with EB and $P$. One group received $10 \mu \mathrm{g} / \mathrm{kg} \mathrm{EB}$ and the second $5 \mu \mathrm{g} / \mathrm{kg}$ EB over 3 successive weeks. Each week a different anti-estrogen dose was administered $20 \mathrm{~min}$ prior to EB injection. 


\section{EXPERIMENT II}

Although the mechanisms by which $\mathrm{CI} 628$ can suppress female sexual responsiveness are unknown, competitive inhibition of estradiol uptake in relevant target sites may account for these behavioral effects. This hypothesis would be supported by demonstrating that the anti-estrogenic effects of $\mathrm{CI}$ 628 could be modified by altering the ratio of estrogen and antiestrogen doses administered concurrently. In this experiment, both the EB and the CI 628 dose were varied to test the competitive inhibition hypothesis.

\section{Methods}

Eleven ovariectomized females were administered the standard EB $+\mathrm{P}$ priming sequence; anti-estrogen tests were conducted once during each of the following 2 weeks. For these tests the CI 628 dose remained at $1.0 \mathrm{mg} / \mathrm{animal}$ and was injected at zero-hr ( 20 min prior to EB), but the quantity of EB was increased to $20 \mu \mathrm{g} / \mathrm{kg}$. This dose is 16 times threshold (Powers and Valenstein, 1972). Approximately half the females were treated with anti-estrogen, and half with control injections $(0.1 \mathrm{ml} 5 \%$ ethanol). These conditions were reversed on the second week so that all animals received both treatments. A second series of tests was begun 1 month later in which all conditions remained the same except that $1.0 \mathrm{mg} \mathrm{Cl} 628$ or vehicle was administered at both zero- and 6-hr. Thus for this sequence of two weekly behavior tests, the estrogen dose remained the same $(20 \mu \mathrm{g} / \mathrm{kg} \mathrm{EB})$ but the anti-estrogen dose was increased to $2.0 \mathrm{mg} /$ animal.

\section{Results}

The sexual responsiveness of females treated with EB doses considerably above threshold $(20 \mu \mathrm{g} / \mathrm{kg})$ was somewhat at tenuated by $1.0 \mathrm{mg} \mathrm{Cl} 628$ at zero-hr (Fig. 2). Although this behavioral suppression was by no means as pronounced as it was with EB doses of 5 or $10 \mu \mathrm{g} / \mathrm{kg}$ (Fig. 1), the difference between anti-cstrogen and control treatments was significant $(p<.05$; Wilcoxon test). This anti-estrogenic effect was further enhanced by injecting $1.0 \mathrm{mg}$ of CI 628 at both zero-hr and 6-hr (Fig. 2). In this case the control and experimental mean receptivity scores were 2.3 and 1.2 , respectively $(p<0.01$, Wilcoxon test). Thus with identical estrogen doses $(20 \mu \mathrm{g} / \mathrm{kg})$, $2.0 \mathrm{mg}$ of CI 628 divided between zero-hr and 6-hr injections suppressed the mean RS to 1.2 , whereas $1.0 \mathrm{mg}$ of anti-estrogen at zero-hr alone did not have as great an effect $(\mathrm{RS}=1.8)$.

\section{EXPERIMENT III}

It is generally considered that receptive behavior in female rodents can be more easily induced by esterified estrogens (e.g. EB) than by the free 

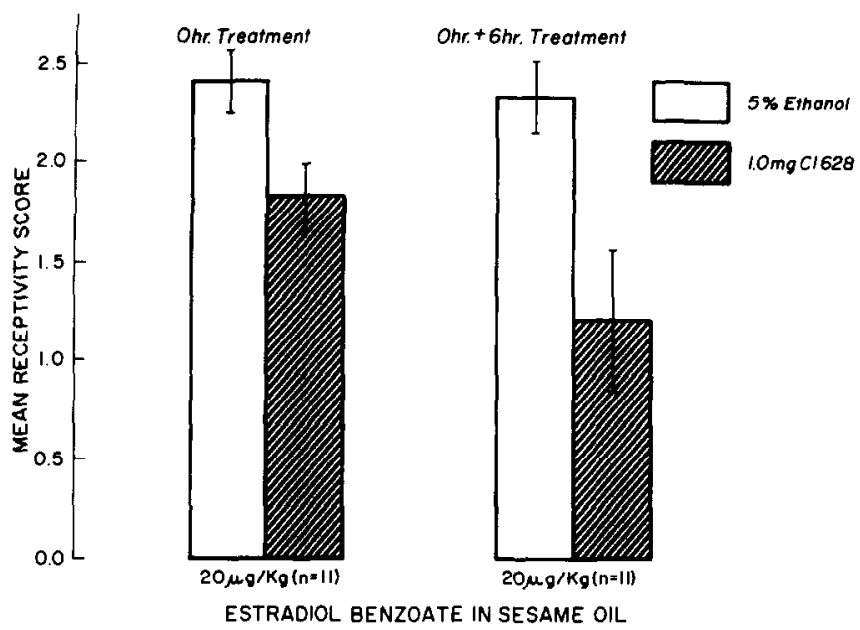

Fig. 2. Receptivity scores (mean \pm SEM) of ovariectomized rats treated with EB and P. CI 628 or vehicle injections were given to females administered $20 \mu \mathrm{g} / \mathrm{kg}$ EB either at zero-hr or at zero-hr and at 6 -hr.

alcohol form (Feder and Silver, 1974). Additionally, it has been reported that anti-estrogenic suppression of lordosis in rats is more difficult to accomplish when estradiol rather than EB is the estrogenic stimulus (Meyerson and Lindstrom, 1968). This finding seemed contradictory to the results of Experiments I and II in that the most effective estrogen stimulus (the highest EB dose) was the most resistant to anti-estrogenic suppression. In order to test the ability of $\mathrm{Cl} 628$ to antagonize estradiol-induced sexual responsiveness, it was first necessary to determine the sensitivity of our animals to this form of the steroid so that behaviorally comparable doses of $E$ and EB could be chosen. This was accomplished by obtaining thresholds for estradiol-stimulated lordosis using techniques previously established in this laboratory (Powers and Valenstein, 1972).

\section{Methods}

Twenty-two ovariectomized females were maintained under standard laboratory conditions. The general objective of the threshold procedure was to determine behavioral sensitivity to estradiol by measuring lordosis responses following estradiol and progesterone injections as the dose of estradiol was systematically reduced over successive weeks until estrous behavior could no longer be elicited. For the first week of treatment, the standard $E B+P$ priming sequence was given. Seven days later, weekly injections of estradiol in $0.9 \%$ saline (sc) were begun. Each week, the behavioral tests and the $\mathrm{P}$ 
injections preceding them were carried out as described in the general procedures. The initial $\mathrm{E}$ dose was $80 \mu \mathrm{g} / \mathrm{kg}$ which was reduced by one-half each week until a threshold criterion had been met. For each animal, an $\mathrm{E}$ dose was considered threshold when the receptivity score was 0.2 or below. However, if a score of 0.2 or below was obtained when the preceding week's RS was 1.0 or greater, the test was repeated the following week at the same $\mathrm{E}$ dose. If the RS was again 0.2 or below, this quantity of estradiol was considered a valid threshold; if the score was above this level, the E dose was halved the following week. Thus, estradiol quantities were systematically reduced over successive weeks until the dose administered was no longer sufficient to induce lordosis.

\section{Results}

The behavioral sensitivity of ovariectomized females to exogenous estradiol is considerably less than the comparable sensitivity to estradiol benzoate. Table 1 shows the mean receptivity scores at each of the estradiol doses used in the testing procedure; females are grouped according to the thresholds they eventually attained. The mean $\mathrm{E}$ threshold of $9 \mu \mathrm{g} / \mathrm{kg}$ is approximately seven times greater than the EB threshold $(1.25 \mu \mathrm{g} / \mathrm{kg})$ measured previously in this laboratory using similar procedures (Powers and Valenstein, 1972). The majority of animals had E thresholds of either $5 \mu \mathrm{g} / \mathrm{kg}$ or $10 \mu \mathrm{g} / \mathrm{kg}$; values outside this range were achieved by only two of 22 females. They were $20 \mu \mathrm{g} / \mathrm{kg}$ and $2.5 \mu \mathrm{g} / \mathrm{kg}$, respectively. With very few exceptions, females displayed a systematic reduction in the intensity of lordosis as the quantity of estradiol administered was decreased over successive weeks.

TABLE 1

Sexual Receptivity Scores for OVX Females Displaying Varying Estradiol Thresholds ${ }^{a}$

\begin{tabular}{|c|c|c|c|c|c|c|c|}
\hline \multirow[t]{2}{*}{$\begin{array}{l}\text { Threshold } \\
(\mu \mathrm{g} / \mathrm{kg})\end{array}$} & \multirow[t]{2}{*}{$(N)$} & \multicolumn{6}{|c|}{ Estradiol dose $(\mu \mathrm{g} / \mathbf{k g})^{b}$} \\
\hline & & 80 & 40 & 20 & 10 & 5 & 2.5 \\
\hline 2.5 & (1) & 2.9 & 2.7 & 3.0 & 2.5 & 0.8 & 0.0 \\
\hline 5.0 & (5) & $2.6 \pm 0.13$ & $1.6 \pm 0.55$ & $2.2 \pm 0.51$ & $1.5 \pm 0.23$ & $0.04 \pm 0.04$ & - \\
\hline 10 & (15) & $2.8 \pm 0.10$ & $2.4 \pm 0.15$ & $1.6 \pm 0.17$ & $0.03 \pm 0.02$ & - & - \\
\hline 20 & (1) & 1.8 & 1.0 & 0.00 & - & - & - \\
\hline
\end{tabular}

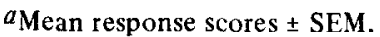

$b_{0.5} \mathrm{mg}$ progesterone was administered $42 \mathrm{hr}$ following estradiol. 


\section{EXPERIMENT IV}

The mcan cstradiol threshold determined in Experiment III allowed an E dose to be chosen for use with $\mathrm{Cl} 628$ which could be equated with the two EB doses used in Experiment I. Quantities for injection were chosen so that the ratio of estrogen dose/estrogen threshold would be identical for both estradiol and estradiol benzoate. This implicitly assumes that over the dose range used, the relation between estrogen quantity and intensity of receptive behavior is described by a linear log dose-response function, and that the slopes are identical for both $\mathrm{E}$ and $\mathrm{EB}$.

\section{Methods}

One week following an $\mathrm{EB}+\mathrm{P}$ priming sequence, 21 ovariectomized females were randomly divided into one of two estradiol dosage groups. The doses used were 36 or $72 \mu \mathrm{g} / \mathrm{kg}$, because the ratio of these values to threshold $(36 / 9$ or $72 / 9)$ is equivalent to the ratio of 5 or $10 \mu \mathrm{g} / \mathrm{kg} \mathrm{EB}$ to EB threshold $(5 / 1.25$ or $10 / 1.25)$. Each female was tested for sexual receptivity over 2 successive weeks; the estradiol dose remained constant, but anti-estrogen conditions varied. At zero-hr ( $20 \mathrm{~min}$ prior to E) approximately half the females in both E groups ( 36 or $72 \mu \mathrm{g} / \mathrm{kg}$ ) received $1 \mathrm{mg} \mathrm{CI} 628$, while the remainder were administered vehicle injection ( 0.1 of $5 \%$ ethanol). These treatments were reversed the following week, and on both occasions progesterone injections and behavior testing occurred at 42-and 48-hrs, respectively.

\section{Results}

High levels of receptive behavior were induced by both quantities of estradiol (Fig. 3). Although females were slightly less responsive to male mounts following CI 628 treatment, the differences between anti-estrogen and control conditions were not significant in either of the cstradiol dosage groups. Because the mean RS following $36 \mu \mathrm{g} / \mathrm{kg} \mathrm{E}+$ vehicle injection was somewhat higher than the maximal responses to 5 or $10 \mu \mathrm{g} / \mathrm{kg}$ EB (Experiment I), it could be argued that $36 \mu \mathrm{g} / \mathrm{kg}$ estradiol was not equivalent to $5 \mu \mathrm{g} / \mathrm{kg}$ EB in its effects on lordosis. Because of this, an additional group of females was tested with a quantity of estradiol less than $36 \mu \mathrm{g} / \mathrm{kg}$. Nineteen of the animals on which estradiol thresholds had been obtained were given the standard EB $+\mathrm{P}$ priming sequence. One week later all females were administered $40 \mu \mathrm{g} / \mathrm{kg} \mathrm{E}$, together with either $1.0 \mathrm{mg} \mathrm{CI} 628(n=10)$ or $0.1 \mathrm{ml} 5 \%$ ethanol $(n=9)$ at zero-hr $(20 \mathrm{~min}$ prior to E). Progesterone injections and behavior tests were carried out in standard fashion. On the following week the estradiol dose was decreased to $20 \mu \mathrm{g} / \mathrm{kg}$ for all females with anti-estrogen or vehicle, again given at zero-hr to 10 and nine animals, respectively. Each of 
these two groups was comprised of approximately equal numbers of animals having received either anti-estrogen or vehicle during the previous week. The receptivity scores following these treatments are shown in Fig. 4.

CI 628 suppressed lordosis behavior induced by both 40 and $20 \mu \mathrm{g} / \mathrm{kg} \mathrm{E}$, but in neither case was this attenuated responsiveness a significant effect.
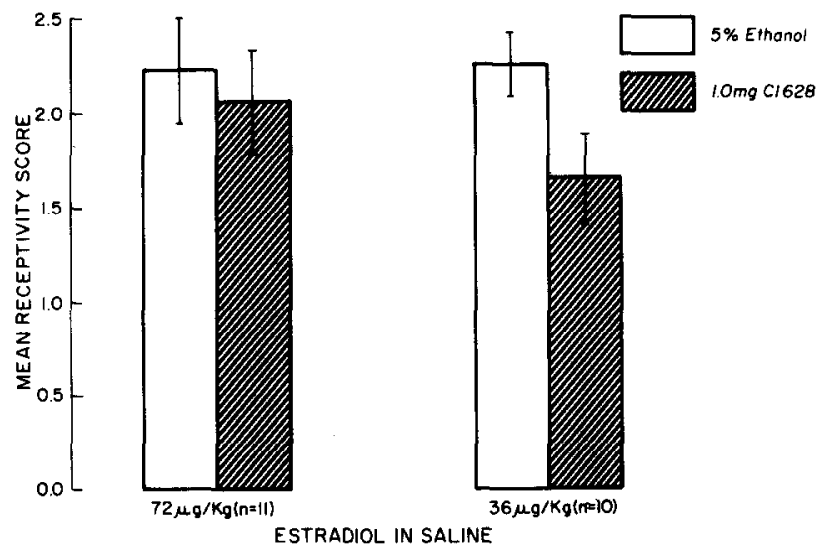

Fig. 3. Receptivity scores (mean \pm SEM) of ovariectomized rats treated with $E$ and P. One group received $72 \mu \mathrm{g} / \mathrm{kg} \mathrm{E}$, and the second $36 \mu \mathrm{g} / \mathrm{kg}$ E over 2 successive weeks. Each week, either CI 628 or vehicle injections were administered $20 \mathrm{~min}$ prior to $\mathrm{E}$ injection.

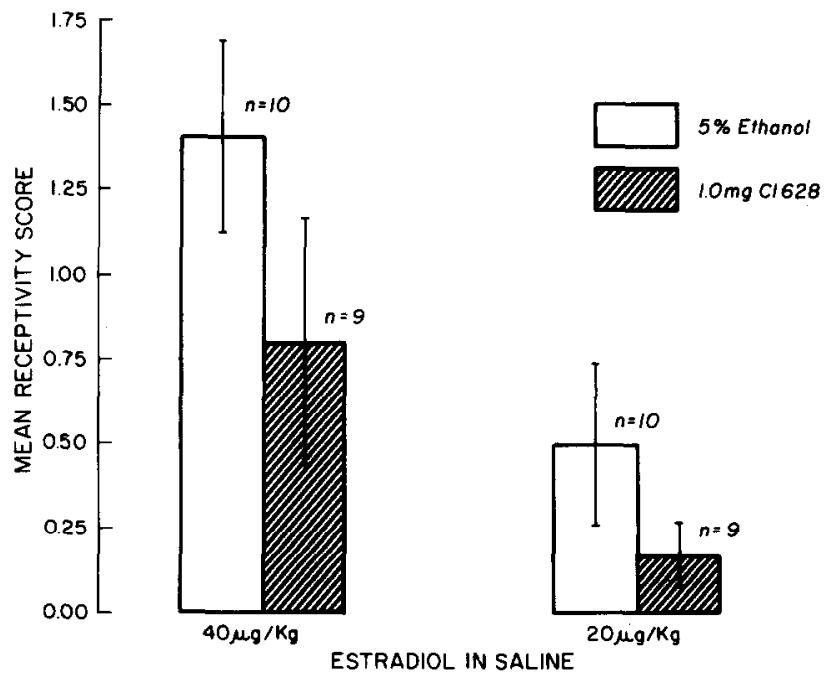

Fig. 4. Receptivity scores (mean \pm SEM) of ovariectomized rats treated with $E$ and P. During one testing series CI 628 or vehicle injections were given 20 min prior to $40 \mu \mathrm{g} / \mathrm{kg} \mathrm{E}$. On a later test, similar injections preceded $20 \mu \mathrm{g} / \mathrm{kg} \mathrm{E}$ treatment. 
Because estradiol threshold values were available for these females (Table 1), it was possible to determine whether the variability in receptivity scores following anti-estrogen treatment was related to individual responsiveness to estradiol. The correlation between $\mathrm{E}$ threshold (Experiment III) and receptivity score $(40 \mu \mathrm{g} / \mathrm{kg} \mathrm{E}+1.0 \mathrm{mg} \mathrm{Cl} 628-$ this experiment $)$ was $-0.90(p<.01$, Spearman rho) indicating that anti-estrogen treatment was less effective the lower a female's threshold to estradiol. This suggests that the greater an animal's sensitivity to estrogen, the greater the quantities of anti-estrogen required to suppress estrogen's effect on lordosis.

\section{DISCUSSION}

CI 628 is a potent antagonist of estrogen-induced sexual receptivity in ovariectomized female rats (Experiment I). The pharmacologic suppression of behavioral estrus demonstrated here is consistent with the observations of others using this compound (Arai and Gorski, 1968; Whalen and Gorzalka, 1973) as well as other anti-estrogens (Komisaruk and Beyer, 1972; Ross, et al., 1973; McDonald, 1973). The effects of $\mathrm{Cl} 628$ on female sexual responding are dose dependent (Figs. 1,2). Under the testing conditions used here, $1.0 \mathrm{mg}$ of CI 628 significantly inhibited the effectiveness of 5,10 , and $20 \mu \mathrm{g} / \mathrm{kg}$ EB. However, the magnitude of this effect varied systematically with the quantity of EB administered. Lordosis inhibition was attenuated either by increasing the EB or decreasing the anti-estrogen dose. In addition, the inhibitory effect was enhanced by injecting greater quantities of $\mathrm{Cl} 628$ and lengthening the time over which it could act (Fig. 2). The nature of this dose-response relation suggests that CI 628 may compete with estradiol for neural receptor sites relevant to behavioral functions. Competitive inhibition is generally considered one of the primary mechanisms of anti-estrogenic action, at least in peripheral target tissues (Callantine, 1967; Geynet, et al., 1972). There is some suggestion that CI 628 may not inhihit estradiol uptake in the central nervous system (Whalen and Gorzalka, 1973). However, others have demonstrated that $\mathrm{Cl} 628$ can suppress hypothalamic estradiol uptake (Perry, DiPasquale, Ferguson, Pozzi, and Rassaert, 1973) although this inhibition occurred in intact, but not in ovariectomized, females. There is little doubt that other pharmacologic agents can effectively compete for estradiol receptors in brain (Kahwanlago, Heinrichs, and Hermann, 1970; van Kordelaar, Broekman, and van Rossum, 1975; Maurer and Wooley, 1971). A more precise characterization of $\mathrm{Cl} 628$ effects on estrogen interactions with neural tissue will require assessment of estradiol uptake by cytoplasmic and nuclear receptors in a variety of brain sites. It is unlikely that the inhibitory effects of CI 628 on estrogen-induced sexual behavior are mediated peripherally. Preliminary evidence has been obtained in this laboratory that placement of $\mathrm{Cl}$ 
628 directly into diencephalic estrogen target sites can be as effective as systemic injection in suppressing sexual responsiveness.

Free estradiol is a less effective hormonal stimulus for inducing receptive behavior than is estradiol benzoate (Table 2; Feder and Silver, 1974; Meyerson and Lindstrom, 1968). Estradiol thresholds were approximately seven times greater than EB thresholds obtained under identical testing situations (Powers and Valenstein, 1972). The reason for this difference is not known, but it probably involves differential rates of estradiol release into the systemic circulation and subsequent metabolic clearance. Blood levels of estradiol remain elevated for a longer duration following injection of $E B$ in oil than they do following an injection of $E$ in oil (Tapper, Grieg and Brown-Grant, 1974). Additionally, $\mathrm{E}$ administered in an oil vehicle remains in the circulation for a longer time than does $E$ injected in saline (Jensen, DeSombre, Hurst, Kawashima and Jungblut, 1967). However, the differences in behavioral responsiveness to $\mathrm{E}$ and $\mathrm{EB}$ (Experiment III) cannot be due solely to the injection vehicle used (saline vs sesame oil) because Meyerson and Lindstrom (1968) found comparable differences in behavioral effect between E and EB when sesame oil was the vehicle used for both hormones.

CI 628 is considerably less effective in suppressing E- compared to EB-induced lordosis (Figs. 2, 3). This difference has also been reported using the anti-estrogen, MER-25 (Meyerson and Lindstrom, 1968). The choice of E doses to be tested with $\mathrm{CI} 628$ in Experiment IV was based on the assumption that the functions relating $\log$ estrogen dose to behavioral responsiveness were essentially identical for E and EB. Specifically, it was assumed that doses five times both $E$ and $E B$ thresholds would induce equivalent behavioral effects, but there are no data in the present experiments to either refute or confirm this assumption. Although it is possible that the failure of $\mathrm{Cl} 628$ to significantly attenuate receptive behavior induced with either 36 or $40 \mu \mathrm{g} / \mathrm{kg} \mathrm{E}$ was due to these doses being equivalent to quantities of EB considerably greater than $5 \mu \mathrm{g} / \mathrm{kg}$, a more likely alternative is presented below.

It can be hypothesized that in order to achieve optimal estrogen conditioning for behavioral estrus, some minimum level of estradiol must be maintained in the blood and available for interaction with brain for a sufficient time period before progesterone can facilitate the lordosis response. This period is generally thought to be at least 18 hours (Quadagno, McCullough, and Langan, 1972) although in some rodent species it may be considerably longer (Feder and Morin, 1974). Because blood levels of estradiol return to baseline much more rapidly after injections of $E$ than they do after injections of EB (Tapper et al., 1974), higher doses of E relative to EB would be necessary to achieve this optimal estrogen level throughout the necessary time period. Thus early in the estrogen conditioning period effective doses of free estradiol provide quantities of steroid considerably in excess of those 
required for an optimum response. In the case of EB injection, initial estradiol levels are not dramatically above this level but are maintained there for a relatively long duration. The most likely reason that CI 628 fails to suppress estradiol-induced behavior then is because of this initial excess hormone titer which remains uninhibited and available for interaction with receptor sites in brain.

Recent studies have demonstrated that brain implants of anti-estrogen can be used successfully to identify sites of positive feedback control of estrogen on LH release (Bainbridge and Labhsetwar, 1971; Billard and McDonald, 1973). The results of the present experiments make it apparent that CI 628 may be an extremely useful tool for exploring the relevance of various estrogen target sites within the limbic system to behavioral functions.

\section{ACKNOWLEDGMENTS}

This research was supported by NIH Grant No. $201 \mathrm{MH}$ 20811-03 to Elliot S. Valenstein. Dr. Jerry R. Reel, Parke, Davis \& Co., supplied the Cl 628 and Dr. Irving Tabachnick, Schering Corporation, provided the estrogens and progesterone. I wish especially to thank Denise Fleming and Trish Britten for conducting most of the behavioral testing.

\section{REFERENCES}

Arai, Y. and Gorski, R. A. (1968). Effect of anti-estrogen on steroid induced sexual receptivity in ovariectomized rats. Physiol. Behav. 3, 351-353.

Bainbridge, J. G. and Labhsetwar, A. P. (1971). The role of oestrogens in spontaneous ovulation: Location of site of action of positive feedback of oestrogen by intracranial implantation of the anti-oestrogen I.C.I. 46, 474. J. Endocrinol. 50, 321-327.

Beach, F. A. and Orndoff, R. K. (1974). Variation in the responsiveness of female rats to ovarian hormones as a function of preceding hormonal deprivation. Horm. Behav. 5, 201-205.

Billard, R. and McDonald, P. G. (1973). Inhibition of ovulation in the rat by intrahypothalamic implants on an antioestrogen. J. Endocrinol. 56, 585-590.

Callantine, M. R. (1967). Nonsteroidal estrogen antagonists. Clin. Obstet. Gynecol. 10 , 74-87.

Callantine, M. R., Humphrey, R. R., Lee, S. L., Windsor, B. L., Schottin, N. H., and O'Brien, O. P. (1966). Action of an estrogen antagonist on reproductive mechanisms in the rat. Endocrinology 79, 153-167.

Ciaccio, L. A. and Lisk, R. D. (1973). Central control of estrous behavior in the female golden hamster. Neuroendocrinology 13, 21-28.

Davidson, J. M. (1972). Hormones and reproductive behavior. In S. Levine (Ed.), Hormones and Behavior, pp. 63-103 Academic Press, New York.

Feder, H. H. and Morin, L. P. (1974). Suppression of lordosis in guinea pigs by ethamoxy-triphetol (MER-25) given at long intervals (34-46 hr) after estradiol benzoate treatment. Horm. Behav. 5, 63-71. 
Feder, H. H. and Silver, R. (1974). Activation of lordosis in ovariectomized guinea pigs by free and esterified forms of estrone, estradiol-17 $\beta$ and estriol. Physiol. Behav. 13, 251-255.

Geynet, C., Millet, C., Truong, H., and Baulieu, E. E. (1972). Estrogen and anti-estrogens. Gynecol. Invest. 3, 2-29.

Gorski, R. A. (1974). The neuroendocrine regulation of sexual behavior. In G. Newton and A. H. Riesen (Eds.), Advances in Psychobiology, Vol. 2, pp. 1-58. John Wiley \& Sons, New York.

Jensen, E. V., DeSombre, E. R., Hurst, D. J., Kawashima, T., and Jungblut, P. W. (1967). Estrogen-receptor interactions in target tissues. Arch. Anat. Microsc. 56, 547-569.

Kahwanago, I., Heinrichs, W. L., and Hermann, W. L. (1970). Estradiol "receptors" in hypothalamus and anterior pituitary gland: Inhibition of estradiol binding by SH-group blocking agents and clomiphene citrate. Endocrinology 86, 1319-1326.

Komisaruk, B. R. and Beyer, C. (1972). Differential antagonism by MER-25, of behavioral and morphological effects of estradiol benzoate in rats. Horm. Behav. 3, 63-70.

van Kordelaar, J. M. G., Brockman, M. M. M., and van Rossum, J. M. (1975). Interaction of contraceptive progestins and related compounds with the oestrogen receptor. Part I: Effect on $\left[{ }^{3} \mathrm{H}\right]$ oestradiol pattern in the ovariectomized rat. Acta Endocrinol. 78, 145-164.

Kow, L-M., Malsbury, C. W., and Pfaff, D. W. (1974). Effects of progesterone on female reproductive behavior in rats: Possible modes of action and role in behavioral sex differences. In W. Montagna and W. A. Sadler (eds.), Reproductive Behavior, pp. 179-210. Plenum Press, New York.

Lisk, R. D. (1973). Hormonal regulation of sexual behavior in polyestrous mammals common to the laboratory. In R. O. Greep (Ed.), Handbook of Physiology, Section 7: Endocrinology, Vol. 2, Part 1, pp. 223-260. American Physiological Society, Washington, D. C.

Luttge, W. G., Wallis, C. J., and Hall, N. R. (1974). Effects of pre- and post-treatment with unlabeled steroids on the in vivo uptake of $\left[{ }^{3} \mathrm{H}\right]$ progestins in selected brain regions, uterus and plasma of the female mouse. Brain Res. 71, 105-115.

Maurer, R. and Wooley, D. (1971). Distribution of $\left[{ }^{3} \mathrm{H}\right]$ estradiol in clomiphene-treated and neonatally androgenized rats. Endocrinology 88, 1281-1287.

McDonald, P. G. (1973). The effect of lypothalamic stimulation and progesterone on ovulation in female rats treated with the oestrogen antagonist ICI 46,474. Acta Endocrinol. 72, 345-350.

McEwen, B. S., Zigmond, R. E., and Gerlach, J. L. (1972). Sites of steroid binding and action in the brain. In G. H. Bourne (Ed.), The Structure and Function of Nervous Tissue, Vol. 5, pp. 205-291. Academic Press, New York.

Meyerson, B. J. and Lindstrom, L. (1968). Effect of an oestrogen antagonist ethamoxytriphetol (MER-25) on oestrous behaviour in rats. Acta Endocrinol. 59, 41-48.

Morin, L. P. and Feder, H. H. (1974). Hypothalamic progesterone implantation and facilitation of lordosis behavior in estrogen-primed ovariectomized guinea pigs. Brain Res. 70, 81-94.

O'Malley, B. W. and Means, A. R. (1974). Female steroid hormones and target cell nuclei. Science 183, 610-620.

Perry, K., DiPasquale, G., Ferguson, E., Pozzi, C., and Rassaert, C. L. (1973). Action of an estrogen antagonist in intact and ovariectomized rats. Contraception 7 , 231-242.

Paff, D. W. and Keiner, M. (1973). Atlas of estradiol-concentrating cells in the central nervous system of the female rat. J. Comp. Neurol. 151, 121-158. 
Powers, J. B. (1972). Facilitation of lordosis in ovariectomized rats by intracerebral progesterone implants. Brain Res. 48, 311-325.

Powers, J. B. and Valenstein, E. S. (1972). Individual differences in sexual responsiveness to estrogen and progesterone in ovariectomized rats. Physiol. Behav. 8, 673-676.

Quadagno, D. M., McCullough, J., and Langan, R. (1972). The effect of varying amounts of exogenous estradiol benzoate on estrous behavior in the rat. Horm. Behav. 3, 175-179.

Ross, J. W., Paup, D. C., Brant-Zawadzki, M., Marshall, J. R., and Gorski, R. A. (1973). Effects of cis- and trans-clomiphene in the induction of sexual behavior. Endocrinology 93, 681-685.

Sar, M. and Stumpf, W. E. (1973). Neurons of the hypothalamus concentrate $\left[{ }^{3} \mathrm{H}\right]$ progesterone or its metabolites. Science 182, 1266-1268.

Seiki, K. and Hattori, M. (1973). In vivo uptake of progesterone by the hypothalamus and pituitary of the female ovariectomized rat and its relationship to cytoplasmic progesterone-binding protein. Endocrinol. Japon. 20, 111-119.

Tapper, C. M., Grieg, F., and Brown-Grant, K. (1974). Effects of steroid hormones on gonadotrophin secretion in female rats after ovariectomy during the oestrous cycle. J. Endocrinol. 62, 511-525.

Wade, G. N., Harding, C. F., and Feder, H. H. (1973). Neural uptake of $\left[1,2-{ }^{3} \mathrm{H}\right]$ progesterone in ovariectomized rats, guinea pigs and hamsters: Correlation with species differences in behavioral responsiveness. Brain Res. 61, 357-367.

Whalen, R. E. and Gorzalka, B. B. (1973). Effects of an estrogen antagonist on behavior and on estrogen retention in neural and peripheral target tissues. Physiol. Behav. $10,35-40$.

Whalen, R. E. and Gorzalka, B. B. (1974). Estrogen-progesterone interactions in uterus and brain of intact and adrenalectomized immature and adult rats. Endocrinology 94, 214-223. 